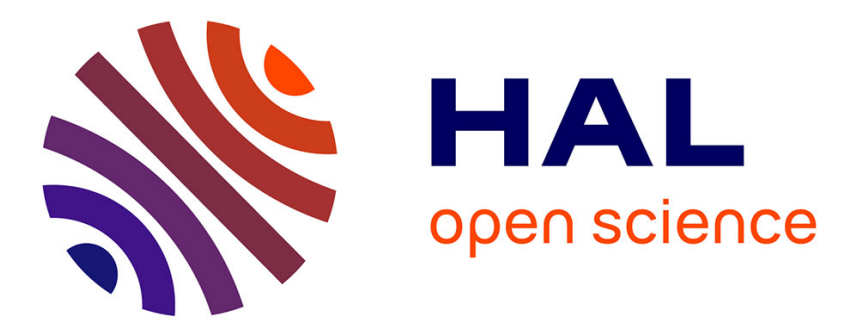

\title{
Fluid-soil-structure interaction in liquefaction around a cyclically moving cylinder
}

Pierre Foray, D. Bonjean, Hervé Michallet, Mathieu Mory

\section{To cite this version:}

Pierre Foray, D. Bonjean, Hervé Michallet, Mathieu Mory. Fluid-soil-structure interaction in liquefaction around a cyclically moving cylinder. Journal of Waterway, Port, Coastal, and Ocean Engineering, 2006, 132 (4), pp.289-299. 10.1061/(ASCE)0733-950X(2006)132:4(289) . hal-00260296

\section{HAL Id: hal-00260296 \\ https://hal.science/hal-00260296}

Submitted on 20 Feb 2020

HAL is a multi-disciplinary open access archive for the deposit and dissemination of scientific research documents, whether they are published or not. The documents may come from teaching and research institutions in France or abroad, or from public or private research centers.
L'archive ouverte pluridisciplinaire HAL, est destinée au dépôt et à la diffusion de documents scientifiques de niveau recherche, publiés ou non, émanant des établissements d'enseignement et de recherche français ou étrangers, des laboratoires publics ou privés. 


\title{
Fluid-soil-structure interaction in liquefaction around a cyclically moving cylinder
}

\author{
P. Foray ${ }^{1}$, D. Bonjean ${ }^{1}$, H. Michallet ${ }^{2}$, M. Mory ${ }^{3}$ \\ ${ }^{1}$ Laboratoire 3S (UJF-INPG-CNRS), BP 53, 38041 Grenoble Cedex 9, France \\ ${ }^{2}$ LEGI (UJF-INPG-CNRS), BP 53, 38041 Grenoble Cedex 9, France \\ ${ }^{3}$ ENSGTI (Université de Pau et des Pays de l’Adour), BP 7511, 64075 Pau Cedex France
}

\begin{abstract}
Coastal or offshore structures such as pipelines installed on the seabed are submitted to cyclic horizontal loads either by the direct hydrodynamic action of waves or through the cyclic movement of risers or flow lines transmitted by floating structures. In fine sandy or silty soils these cyclic loads can induce a liquefaction of the surrounding bed, which can play an important part in the processes of erosion, trenching or self-burial of the pipes. As part of the LIMAS program, a full-scale physical model was built to study the fluid-soil-structure interaction with special emphasis on the conditions leading to liquefaction around a pipe instrumented with pore pressure sensors. The experiments indicate a development of excess pore pressure at the pipe-soil interface much higher than the effective overburden stress, and a lateral visualisation provided evidence of the liquefaction of a soil band in the vicinity of the pipe. The penetration of the structure can be related to the phenomenon of liquefaction.
\end{abstract}

\section{Introduction}

According to field observations, liquefaction seems to play an important part in erosion and stability problems for coastal structures, such as breakwaters or pipelines. Theoretical approaches have been devoted to the conditions that produce liquefaction of the entire seabed due to the cyclic shear loading induced by waves, (see Sumer et al (1999), Sassa et al (2001), Cheng et al (2001)). Damgaard and Palmer (2001) discussed the order of magnitude of the different processes leading to the instability of pipes and found that the hydrodynamic forces necessary to laterally move a pipe resting on the seabed cause sediment transport and liquefaction before a significant movement of the pipe occurs. On the another hand, wave induced hydrodynamic pressures can create a cyclic loading of structural foundations which 
can lead to more local liquefaction phenomena. Within the framework of the European program LIMAS (“Liquefaction around Marine Structures”), experimental research was carried out in the laboratory to study the conditions that lead to wave induced liquefaction of the soil close to a marine structure and the consequences on its stability.

The first scenario considered was the response of a large area of seabed with a structure such as a pipe resting on the seafloor or partially/completely buried in the soil. This scenario was simulated by Sumer et al (1999) and Teh et al (2003) who conducted tests in sand or silt flumes with model pipes free to move. Liquefaction of the entire seabed could be observed and its effects on sinking or floatation of pipelines were studied.

A second scenario corresponds to the case where the cyclic wave loading applied to a structure is transmitted to the soil by its foundations or connections. A typical example is the cyclic movements of a floating structure that are transmitted by catenary risers to their touchdown point on the seabed, as shown on Figure 1. The estimation of the pipe-soil interaction is an important issue in the design of the pipe structure, especially at the "touchdown point”.

As part of the same LIMAS program, a series of tests corresponding to this second scenario was performed at the University of Grenoble. These tests focused on fluid-soil-structure interaction and the simulation by use of mechanical actuators of the cyclic wave action on pipes resting on a sand bed.

Pipe-soil interaction has been studied extensively by many authors, such as Lyons (1973), Lambrakos (1985), Brennoden et al. (1986), Wagner et al. (1987), Palmer et al. (1988), Morris et al. (1988). These authors demonstrated the process of self-burial of structures resting on the seabed induced by wave action. They proposed guidelines for the lateral resistance of the pipes and design criteria for their stability. A previous experimental program had been conducted at the University of Grenoble by Branque et al $(2001,2002)$ to quantify the influence of the cyclic amplitude and the density of the sand on the penetration of the pipe and the evolution of the lateral soil resistance. The effects of pipe weight and diameter were also considered. A transitory liquefaction of the soil close to the pipe could be observed for some of the tests, with high peak cyclic excess pore pressures reaching the effective overburden stress. 
In the present program, an emphasis was given to measurements of excess pore pressure at the pipe-soil interface and within the soil during the pipe cyclic loading. The conditions required for liquefaction and their effect on the pipe stability were studied and recorded through a lateral visualisation. The first results were reported by Bonjean et al. (2004) and Foray et al. (2004). The present paper gives a general presentation of the experimental program.

\section{Experimental set up}

\subsection{General settings}

As part of the LIMAS program, large modifications were made to the previous set up constructed at the University of Grenoble by Branque (1998) and similar to the one used in the "Pipestab" research program performed by Brennoden et al. (1986), Wolfram et al. (1987). The objectives were (i) to allow a better control of the loading conditions and (ii) to permit a lateral visualisation of the failure and liquefaction process around the structure. The setup consists of a large rigid tank $2 \mathrm{~m}$ long, $1 \mathrm{~m}$ wide and $1 \mathrm{~m}$ deep, which is filled with sand. One side of the tank is made of two glass sheets about $1 \mathrm{~m} \times 1 \mathrm{~m}$ to allow direct visualisation of the deformation in the sand. Figure 2 presents a general view of the experimental set up.

A trolley supporting a $0.9 \mathrm{~m}$ length pipeline section can roll on two horizontal rails along the length of the upper part of the tank parallel to the windows. The pipe itself is free to move vertically between two sliding guides, and then to penetrate into the sand under its self-weight and the action of the cyclic horizontal loads.

The connection between the section of the pipe and the glass is realized with a rubber joint. Thus it is possible to visualize a 2D cross section of the pipe-soil interaction perpendicular to the axis of the pipe. Moreover, it is possible to record a video of the experiments and provide visual evidence of the occurrence of liquefaction.

\subsection{Loading systems}

A mechanical actuator fixed on the tank can move the trolley horizontally. A load cell links the actuator to the trolley. The actuator is moved via a computer-controlled electrical motor. This set up allows a load-controlled regulation of the actuator which in turn enables the cyclic wave-induced hydrodynamic forces acting on the pipeline to be faithfully reproduced. 
An alternative loading system was also used in order to perform displacement-controlled tests. A crankshaft-connecting rod system converts a circular motor motion into a horizontal sinusoidal movement. Despite the fact that such a device prevents load regulation of the movement, it does allow a much more accurate control of the pipe displacement. Although such loading conditions do not represent exactly the hydrodynamic effects, they are interesting in order to understand the influence of the experimental parameters.

\subsection{Equivalent loading to wave action}

Estimation of the order of magnitude of the cyclic loads to be applied to the pipe was made from hydrodynamic considerations. The wave action on a cylindrical structure can be computed under the following assumptions. We consider linear waves passing over a cylinder at rest (of small velocity compared to the flow velocity). Diffraction effects are neglected (i.e. the diameter of the pipe is small compared to the wavelength) as well as vibrations and turbulent effects. The orbital velocity at the bottom is:

$$
V=\frac{\pi H_{w}}{T \sinh (\lambda h)} \cos \left(\frac{2 \pi t}{T}\right)
$$

where $H_{w}$ is the wave height, $h$ the water depth, $T$ the wave period and $\lambda$ the wave-number defined as:

$$
\lambda \tanh (\lambda h)=\frac{4 \pi^{2}}{g T^{2}} .
$$

The classical Morison (1950) equation (see e.g. Sumer and Fredsøe, 1997) defines the in-line force due to the wave action:

$$
F_{h}=\frac{1}{2} \rho C_{D} D V|V|+\rho C_{M} \frac{\pi D^{2}}{4} \dot{V}
$$

where $C_{D}$ and $C_{M}$ are functions of the Keulegan-Carpenter number (Bryndum et al., 1992). A solution of this equation is shown in Fig.3 for a $1.3 \mathrm{~m}$ high linear wave and a water depth of 2 $\mathrm{m}$. For such a large wave, the linear assumption of the model is certainly a shortcoming. Nevertheless, the applied loading could also schematically represent the cyclic effects of a floating structure linked to flow-lines or risers resting on a deeper seabed.

An example of the force measured on the pipe against its displacement is shown in the same figure. The plot of the measured force is similar to the Morison solution, but more sharply peaked. We note that the maximum displacement is reached as the force attains its maximum value. The pipe then remains more or less at rest for about $1 \mathrm{~s}$ until the force becomes 
sufficiently large in the opposite direction. Next, the variation in the force becomes smoother, as the orbital velocity is close to zero in the model.

\subsection{Pipe instrumentation}

Considering that the effects of pipe diameter and weight per unit length had already been clarified by Branque et al (2002), the same structure was used in the present experiments. This structure consists of a half-pipe with a diameter of $200 \mathrm{~mm}$ and a mass per unit length of 24 $\mathrm{kg} / \mathrm{m}$. The pipe section was instrumented with five Druck PDCR 4030 pore pressure transducers located on the external surface of the pipe in contact with the soil. The pore pressure in the soil is transmitted to the transducer through a porous stone fixed at the connexion between pipe and transducer. This part was carefully saturated before each test. The transducers allow the measurement of a relative pressure up to $7 \times 10^{4} \mathrm{~Pa}$ with a precision of $0.08 \%$. This corresponds to an accuracy in the water height of about $0.5 \mathrm{~mm}$. For some tests, pore pressure transducers were also installed within the sand bed close to the pipe.

The respective positions of the transducers are shown in Figure 4. They were installed at inclinations of $30^{\circ}, 45^{\circ}, 60^{\circ}$ and $90^{\circ}$ with respect to the horizontal plane. As it was not possible to install all five transducers along the same cross section of the pipe, they were fixed on the pipe surface at different sections and in the central part of the pipe in order to eliminate boundary effects. Therefore it is assumed that the distribution of the excess pore pressure is homogeneous along the length of the pipe. For the inclination of $60^{\circ}$, two transducers were installed symmetrically on each side of the pipe in order to verify the symmetry of the mechanisms and the accuracy of the measurements.

\section{Testing Procedure}

\subsection{Sand characteristics}

The Fontainebleau sand used in the tests is a naturally-occurring, uniform, fine silica sand with sub-rounded grains of Tertiary, marine origin. It contents 95 percent of silica. It has been widely used as a standard "academic" sand in geotechnical laboratories in France and its mechanical parameters are known. Its main physical characteristics are:

$D_{50}=0.156 \mathrm{~mm}, C_{\mathrm{u}}=D_{60} / D_{10}=1.47, D_{60}=0.168 \mathrm{~mm}, D_{10}=0.114 \mathrm{~mm}, e_{\max }=1.06$,

$e_{\min }=0.55, \gamma_{\min }=12.87 \mathrm{kN} \mathrm{m}^{-3}, \gamma_{\max }=17.23 \mathrm{kN} \mathrm{m}^{-3}, \gamma_{\mathrm{s}}=26.5 \mathrm{kN} \mathrm{m}^{-3}$. The permeability has a value of $10^{-5} \mathrm{~m} / \mathrm{s}$ for dense sand and $1.5 \times 10^{-5} \mathrm{~m} / \mathrm{s}$ for loose sand. 


\subsection{Sand bed preparation}

Three methods were used to prepare sand beds: (i) dry pluviation followed by saturation of the tank; (ii) pluviation of the sand above the water surface, and (iii) pluviation through the water followed by vibration of the soil.

Dry pluviation-loose sand

A dry pluviation system is used to deposit the sand. The density is controlled by the drop height of the sand through the mesh. A loose sand bed, with a density index $I_{D}$ of about $35 \%$,

was obtained with a zero drop height. The density index is defined as $I_{D}=\frac{e-e_{\min }}{e_{\max }-e_{\min }}$, where $e$ is the void ratio.

\section{Saturation of the sand bed}

Once the sand mass is in place, a very low uplift gradient is applied at the bottom of the tank. A low gradient is used so that all air bubbles in the sand are forced upwards and thus evacuated by the water, instead of being held captive. A gravel layer previously installed at the bottom of the tank and covered by a geotextile membrane ensures a uniform distribution of the hydraulic gradient over the tank surface and a homogeneous saturation of the sand. A good saturation of the sand mass was obtained through this method. After filling the tank with water, the water table is kept at a level of about $10 \mathrm{~cm}$ above the sand surface to ensure it will remain saturated during the movement of the pipe.

Wet method-mid-dense sand

Denser sand beds are prepared by vibrating initially loose sand with a vibratory rod. The vibration process is performed keeping the sand saturated. The density index obtained by this procedure was about $60 \%$.

Wet method - loose sand

In order to maximise the amount of tests performed, it is not necessary to remove, dry and then put back the entirety of the sand in between each test. The reproduction of the loose seabed can be achieved by removing the dense one, and then pouring the sand, again by pluviation above the water surface. Such a procedure produces a loose sand mass whose density was found to be very similar to the one obtained by the dry method.

The homogeneity of the sand bed and the density were controlled by performing light PANDA (Bonjean et al 2004) dynamic penetrometer tests using a rod with a diameter of 20 $\mathrm{mm}$. 
Typical penetration curves obtained in the sand bed are given Figure 5. The penetration depth is expressed in terms of effective overburden pressure $\sigma_{v}^{\prime}\left(\sigma_{v}^{\prime}=\gamma^{\prime} z\right.$, where $\gamma^{\prime}$ is the submerged weight of the soil and $z$ is the depth) and the dynamic resistance is compared to the tip resistance $q_{\mathrm{C}}$ (at the the tip of the cone penetrometer) measured in the same sand during a penetration test performed in the large Calibration Chamber of Laboratoire 3S with a standard static cone of $36 \mathrm{~mm}$ diameter. The differences in the initial stage of the penetration are due to the difference in cone diameter and it can be verified that the steady state tip resistance of both penetrometers are equivalent for the same density. The effective overburden stress of 8 $\mathrm{kPa}$ corresponds to the bottom of the sand bed (about $80 \mathrm{~cm}$ deep).

\section{Testing program}

The tests performed are summarized in Table 1 for the load-controlled tests, all performed using the actuator, and Table 2 for the displacement-controlled tests performed either with the actuator set or with the crankshaft-connecting rod system. For each test, the horizontal cycles were applied after the vertical penetration of the pipe under its self-weight was completed. In the series of load-controlled tests, the experimental parameters explored were the load amplitude ( $\pm 30 \mathrm{daN}$ to $\pm 90 \mathrm{daN}$ ), the loading period ( $2 \mathrm{~s}$ to $8 \mathrm{~s}$ ) and the relative density of the sand (35\% and 60\%). During the tests, the cyclic horizontal displacements were recorded together with the vertical pipe penetration and the pore pressures around the structure.

The displacement-controlled tests cover basically the same experimental parameters. Periods from $1.5 \mathrm{~s}$ to $6 \mathrm{~s}$ were studied in the tests performed with the actuator and a constant period of $15 \mathrm{~s}$ was applied for the tests with the eccentric sinusoidal movement. Amplitudes of the applied lateral displacements of the pipe varied from $\pm 10 \mathrm{~mm}$ to $\pm 80 \mathrm{~mm}$. The corresponding evolution of the lateral force was recorded.

During the last series of tests (D7 and D8), the level of the free surface of the water in the vicinity of the pipe, initially about $10 \mathrm{~cm}$ above the soil surface, was recorded in order to get a more accurate estimation of the effective stresses at the pipe-soil interface and in the soil close to the pipe. Fluctuations of less than $0.1 \mathrm{kPa}$ were recorded, which is of the same order as the variance of the experimental data.

\section{Test results}

\subsection{Pipe Penetration under cyclic loading}




\subsubsection{Influence of the loading period}

Figure 6 represents a typical example of the evolution of the vertical penetration of the pipe with the number of loading cycles for tests in dense sand with a force amplitude of $600 \mathrm{~N}$ and loading periods of 4, 6 and 8 seconds. For a given load amplitude, the highest penetration is observed for the shortest period and little difference is noted between the curves corresponding to 6 and 8 seconds. This result has to be compared to the evolution of the maximum excess pore pressure measured during each cycle along the pipe and shown in Figure 7. On average the highest values of the pore pressure are obtained for the shortest period. This suggests that the shortest period of $4 \mathrm{~s}$ corresponds to loading conditions close to undrained conditions and that a partial drainage occurs for the periods of 6 and 8s. In fact the drainage conditions, and the threshold period under which undrained conditions are fulfilled, are related to the horizontal velocity of the pipe with respect to the sand permeability. However the actuator velocity depends also on the amplitude of the displacements.

These results suggest that for the sand considered in these experiments the typical wave periods of around $12 \mathrm{~s}$ will certainly correspond to partially drained conditions. The effect of shorter periods is equivalent to having a soil of lower permeability (silt), as studied in flumes by the other LIMAS partners (Teh et al. 2003, Sumer et al. 2005).

\subsubsection{Influence of the load amplitude.}

The evolution of the penetration of the pipe as a function of time is represented in Figure 8 for a given period of $6 \mathrm{~s}$ and for three load amplitudes of 300,600 and $900 \mathrm{~N}$. As the period is the same, time is equivalent to the number of cycles.

The value of $900 \mathrm{~N}$ is close to the maximum horizontal resistance of the soil in static conditions and it is logical to find a higher penetration of the pipe for a higher load amplitude. The same trend is observed on the excess pore pressures at the pipe-soil interface shown in Figure 9: the lower pore pressure corresponds to the lowest load.

The tests confirm that a higher penetration and excess pore pressure are obtained when the loading conditions are close to undrained conditions, for both dense and loose sands.

\subsection{Cyclic load-displacement and penetration curves}


Typical cyclic load-displacement loops are presented in Figure 10a for a load-controlled test L8 and in Figure 11 for a displacement-controlled one. Despite some scatter in the experimental data, they show a very similar shape. For a similar load level, the inclination of the loops is governed by the displacement amplitude.

The trajectories followed by the pipe are represented in Figure 10b for the corresponding cyclic loops of Figure 10a, at the end of test L8 (600 N curve after $400 \mathrm{~s}$ in Fig. 8). It can be verified that the maximum penetration occurs when the pipe is in the central part of the trench within the soil zone smoothened by the liquefaction and erosion processes.

The pipe-soil lateral stiffness can be determined by drawing the straight line joining the force peaks, as shown on Figure 11. A remarkable linear and symmetrical response of the loading stage of the pipe can be observed, with stiffness values of $70 \mathrm{~N} / \mathrm{mm}$ (Fig. 11) and $30 \mathrm{~N} / \mathrm{mm}$ (Fig.10a). A very stiff unloading stage corresponds to a change in loading direction.

Similar results are obtained in loose sand. Figure 12 shows an enlargement of the loaddisplacement cycles obtained for Test D8, with a displacement amplitude of $\pm 10.5 \mathrm{~mm}$ and a period of $4.55 \mathrm{~s}$. It can be noted that a plateau of horizontal resistance is obtained for the first cycles and during early penetration. But as the penetration increases and the trenching process tends to stabilize, a stiffening of the last part of the loops appears. This indicates that despite a local liquefaction, a lateral resistance of the soil mass can be mobilized. The average lateral stiffness for test D8 is around $45 \mathrm{~N} / \mathrm{mm}$.

\section{Analysis of Excess Pore Pressure}

\subsection{Excess pore pressure generation}

Figure 13 presents an example of the evolution of the peak values of the excess pore pressure measured by the sensor at $60^{\circ}$ along the pipe. The corresponding values of the vertical effective stress at the same depth have also been plotted, considering that: $\sigma^{\prime}{ }_{\mathrm{v}}=\gamma^{\prime} z$, where $\gamma^{\prime}$ is the submerged weight of the sand and $z$ is the depth at the sensor level. The values of $\sigma^{\prime}$ v are thus increasing with the penetration of the pipe. According to the classical liquefaction analysis, the excess pore pressure needed to liquefy the sand should be equal and not exceed the value of $\sigma_{v}$. It can be noted that during every cycle the excess pore pressure reaches a value much higher than the vertical effective overburden stress. This is certainly due to the fact that, during the lateral pushing of the pipe against the trench sides, the soil close to the 
pipe follows a more complicated undrained or partially drained stress path. Both vertical and lateral effective stresses are increased and the principal axis of the stresses are rotated due to the additional loads induced by the movement of the pipe . Using the simplified model developed by Branque et al (2002), the passive pressures $\sigma^{\prime}{ }_{\text {max }}$ mobilized along the pipe surface at the level of the pore pressure transducer $\left(60^{\circ}\right)$ could be calculated. They correspond to the main principal stresses and, in the case of the present experiments, they were found to be of the order of $6 \mathrm{kPa}$, obviously much higher than $\sigma^{\prime}{ }_{\mathrm{v}}$. The values of the peak pore pressures are intermediate between the passive pressure and the effective overburden pressure $\sigma_{\mathrm{v}}$. This indicates that the practical liquefaction criterion is conservative in this loading case due to the complicated stress path of a soil element in the vicinity of the pipe. An intermediate stress between the passive pressure $\sigma^{\prime}$ max and the effective overburden stress $\sigma^{\prime}{ }_{\mathrm{v}}$, or the mean effective stress $p$ ' would be more appropriate.

The complete history of the cyclic evolution of the excess pore pressure shown in Figure 14 indicates that the maximum excess pore pressure value increases with the number of cycles at the beginning of the loading, but after a few cycles its tends to stabilize, although the pipe continues to sink. This confirms that a critical pore pressure value exists, corresponding to the initiation of the liquefaction observed during each cycle. As mentioned before, this pore pressure is closely related to the mean state of stress in the vicinity of the sensor, which increases only slowly with pipe penetration and gives the apparent plateau shown in Figure 14.

Similar results for the excess pore pressure measured at $60^{\circ}$ for the loose sand are expressed as a function of pipe penetration in Figure 15. The initial penetration stage corresponds to a quasi-linear increase in excess pore pressure. The values of excess pore pressure are $0.2 \mathrm{kPa}$ higher for the lower period (or the lower sand permeability)

The effects of the loading period and amplitude, i.e. the actuator velocity can be analyzed through a nondimensional parameter similar to a Peclet number $\mathrm{VD} / \mathrm{C}_{\mathrm{v}}$ in order to take into account the partial drainage. This problem is similar to the normalization of the excess pore pressure measured during a piezocone test, which depends on the penetration rate $V$ and the dissipation time related to the soil permeability. Such a normalization was suggested by Berrill et al (1992), defining the normalized excess pore pressure $\Delta U$ by:

$\Delta U=\Delta u /\left(t_{50} V \gamma_{\mathrm{w}}\right)$ 
with $\Delta u$ the measured excess pore pressure $(\mathrm{kPa}), t_{50}$ the drainage time (s), $V$ the penetration rate $(\mathrm{cm} / \mathrm{s}), \gamma_{\mathrm{w}}=\rho_{\mathrm{w}} g$ the water unit weight $\left(\mathrm{kN} / \mathrm{m}^{3}\right)$.

Considering that the drainage time is related to the consolidation coefficient $C_{\mathrm{v}}$ of the sand by: $t_{50}=T_{\mathrm{v}} \cdot d^{2} / C_{\mathrm{v}}$

with $T_{\mathrm{v}}$ the time factor (constant), $d$ the drainage distance, $C_{\mathrm{v}}$ the coefficient of consolidation

$\left(\mathrm{cm}^{2} / \mathrm{s}\right)$, a normalized excess pore pressure for the loading of pipes can be written as:

$\Delta U=\Delta u C_{\mathrm{v}} /\left(d^{2} V \gamma_{\mathrm{w}}\right)$

In the case of cyclic pipe loading, $V$ represents the velocity of the actuator and $d$ the drainage distance. In our case $d$ should be taken as the distance between the sensor and the soil surface along the pipe interface and can be easily calculated as a function of pipe penetration and diameter. Such a normalized excess pore pressure allows a uniform presentation of the test results and their extrapolation to soils with lower permeability such as silts.

\subsection{Pore pressure changes during a cycle}

The evolution of the excess pore pressure with the horizontal displacement during the cycles is represented in Fig.16. The graph corresponds to the sensor on the right of the pipe, which explains the unsymmetrical shape of the cyclic loops. As previously shown in Fig.14, each time the pipe changes direction and lifts off from the trench side, strong negative excess pore pressures are measured in the pore fluid. These negative excess pressures are caused by the suction due to soil-structure interaction and their absolute value is greater than the excess pore pressure generated during the loading stage.

When the horizontal $y$ position of the pipe increases, it moves in the direction towards the position of the pore pressure transducers. These are in contact with the trench side for the higher values of $y$ and the pore pressure increases when the pipe is pushing against the trench side. However, slight drops of pressure also appear just before the maximum displacement when $y$ is still increasing. This might correspond to the moment when a critical pore pressure level is reached, and when we observe that the sand starts to flow and behaves like a liquid. This liquefied layer is then pushed off the trench by the pipe, causing large displacements, important shear strains and a trend to dilatancy of this part of the sand. This trend may cause the drop of pressure observed.

Similar observations have been recorded by the transducer at $60^{\circ}$ on the left part of the pipe during the displacement-controlled tests in loose sand. The pushing stage corresponds to the 
upper part of the curves and starts from the right. Again it can be noted that, after developing an excess pore pressure of the order of $0.2 \mathrm{kPa}$, a strong drop occurs leading to negative excess pore pressures before the maximum horizontal displacement is reached. After this drop the excess pore pressure returns to positive values at the end of the loading stage. A sharp suction follows with the lift-off from the trench. The shape of these curves is similar to the "butterfly wings" observed in an undrained triaxial stress path. Dilatancy effects can effectively occur in loose sand considering the very low confining stress around the pipe.

\subsection{Pore pressure distribution along the pipe}

The maximum amplitude of the pore pressure measured around the pipe is at $60^{\circ}$ below the horizontal. The phenomena recorded at $45^{\circ}$ are less important. However, the level reached by the excess pore pressure (about twice the effective vertical stress) seems great enough to liquefy the soil at this location. On the other hand, the sensor set right under the pipe $\left(90^{\circ}\right)$ does not measure any excess pore pressure. This is certainly due to the vicinity of the open trench behind the pipe. The one at $30^{\circ}$ measures only very low variations of the pore

pressure level, possibly due to drainage occurring close to the sand surface. In fact the most significant pore pressure activity occurs in the range between $45^{\circ}$ and $90^{\circ}$. During the same test, the transducer located on the other side of the pipe recorded pressure information very similar to its symmetrical counter part $\left(60^{\circ}\right)$. This confirms that the instrumentation of one side of the pipe is sufficient in our case to monitor the whole burial process.

\subsection{Pore pressure in sand bed close to the pipe}

A series of tests were performed with two pore pressure transducers placed within the soil as shown in Figure 18. The transducers were buried at a depth equal to half the maximum penetration allowed for the pipeline and their minimum distances from the pipe were 20 and $50 \mathrm{~mm}$.

Figure 19 shows the evolution of the excess pore pressure measured by the two transducers within the soil. The qualitative changes in pore pressure measured at the pipe-soil interface are reproduced with an attenuation according to the distance from the pipe.

The transducers show that, even within the soil, suction is felt when the pipe lifts off the trench side. During every cycle, absolute values of the depression peaks remain greater than the value of the excess pore pressure generated. Thus, no general build-up is measured during 
the burial of the pipe since the residual pore pressure level after any cycle is always the hydrostatic level. This behaviour might be different if finer sand were used.

\section{Visualization of Liquefaction}

Some tests were recorded on video so as to allow accurate analysis of the seabed strains around the pipe during burial. An example of two video frames is given in Figure 20. It can be seen clearly from these video stills that a thin (about $1 \mathrm{~cm}$ ) layer of sand close to the pipe behaves like a liquid. It flows away from the trench when the pipe moves towards the bank and then flows under the pipe when it lifts off backwards. The extension of this liquefied zone is maximum at the maximum displacement of the pipe, corresponding to the maximum force and the peak excess pore pressure. It is also noticeable that a significant volume of the sand in front of the pipe is submitted to large strains. The extension of this "plastic" zone corresponding to the area of grain mobility (sand grain motion over the last half-period) is approximately bounded by the dotted line. No general liquefaction of the sand bed was observed.

Similar deformation patterns were recorded in most of the tests performed. In the tests with large amplitude, an open trench was developed behind the pipe.

\section{Guidelines for the estimation of the lateral soil resistance}

The lateral resistance of the pipe-soil system after installation is an important factor for the structural design of pipes. Thus, it is interesting to evaluate the influence of the liquefaction process observed in our tests on the classical stability factors used in the design practice.

The classical stability analysis of exposed pipes on the seabed assumes that the soil-pipe interaction is a Coulomb-type friction law (Veritec 1988). The horizontal resistance $F_{H}$ is expressed as the product of the buoyant weight of the pipe and a friction factor $\mu$ that depends on the nature of the soil. Experimental laboratory studies carried out by Lyons (1973), Brennoden et al. (1986), Palmer et al. (1988) and field tests by Lambrakos (1985) indicate that the Coulomb approach gives satisfactory results in sediments with high bearing capacity such as stiff clays or dense sands, but is only approximate in soil with low bearing capacity. These tests indicate a strong influence of the penetration $z$ of the pipe on the lateral resistance. The model developed by Branque et al (2002) shows that a realistic simulation of the lateral 
resistance mobilized by the soil has to take into account the passive pressure along the side of the pipe. Nevertheless for practical purposes, the sum of the two terms, true frictional resistance and passive resistance, can be expressed as an equivalent friction factor $\mu$ which depends mainly on the relative pipe penetration $z / D$. Figure 21 presents a summary of the equivalent factors $\mu$ obtained by Branque et al. (2002). The ultimate lateral resistance $F h$ of the soil close to the pipe was measured after installation of the pipe at a given depth.

Figure 21 shows that the values of $\mu$ depend mainly on the pipe penetration $z / D$, but also on relative density and pipe diameter. At very low pipe penetrations, $\mu$ represents the true friction coefficient, which is a function of the pipe-soil roughness and is in the order of 0.65 for our tests. For higher values of penetration, $\mu$ incorporates a part of the passive lateral resistance of the soil close to the pipe. The values of this global factor are roughly in agreement with the expression proposed by Palmer et al (1988) indicating a linear increase of $\mu$ with relative penetration $z / D$, but for high penetrations a better fit is obtained with an exponential curve in our tests.

It has to be emphasized that the Ultimate Horizontal resistances measured after horizontal cycling are higher than after initial installation of the pipe at the same depth, with a multiplying factor of about 1.2 .

As a comparison, Figure 22 presents the values of $\mu$ mobilized during the cyclic penetration of the pipe during Test D8. A linear fit is obtained for low relative penetrations, but the values of $\mu$ are higher than the one proposed in Figure 21. For a safe design the values of Figure 21 can be used.

\section{Conclusions}

The visualization of the tests shows evidence of the mechanisms of trenching and local liquefaction in a soil band surrounding the cyclically loaded structure. The observations allow us to evaluate the extent of the "liquefied" and the "plastified" zones.

The results of the tests indicate a strong excess pore pressure increase at the pipe-soil interface during each cyclic horizontal loading of the pipe. This increase is sufficient to create an instantaneous liquefaction in a soil band close to the pipe wall. This liquefaction plays an important role in the trenching and burying process of the structure, as the increments of 
penetration of the pipe correspond to the peaks in excess pore pressure at the pipe-soil interface.

The increase in pore pressure and consequently the penetration of the pipe depends on the soil density, load amplitude and loading period. However, the key factors governing liquefaction are the density and the actuator velocity with respect to the soil permeability, which can lead to loading conditions that produce undrained, partially drained or fully drained behaviour. A nondimensional presentation of the excess pore pressures should enable an extension of the present results to soils with lower permeability.

The recorded excess pore pressures along the pipe are generally higher than the corresponding effective overburden stress due to the complicated stress path of the soil at the pipe interface. Thus the classical liquefaction criterion is not relevant in the vicinity of the pipe.

A strong negative excess pore pressure is noted when inverting the loading direction. Due to this negative excess pore pressure during the unloading stage no general liquefaction of the sand bed was induced by the cyclic movement of the pipe. These aspects are presently being compared to numerical simulations and need further research. Results from this current investigation will be reported in the near future.

The results show the differences in liquefaction development between the case of a structure that undergoes cyclic movements due to hydrodynamics forces acting on its connections (case of the present experiments) and the case of an isolated structured resting or buried in the seabed (experiments carried out by the LIMAS partners). In the first case a local, momentary liquefaction smooths the soil around the pipe and induces large penetrations. This can be part of an erosion process. In the second case a liquefaction of the entire seabed can occur inducing a sinking or flotation of the pipe according to the permeability of the sediments.

The estimation of the evolution of the equivalent friction factor $\mu$ with the relative penetration of the pipe gives some guidelines for a practical safe design of the pipes.

\section{Acknowledgments}

This study was partially funded by the European Commission Research Directorate, FP5, specific program "Energy, Environment and Sustainable Development”, Contract No EVK3CT-2000-00038, Liquefaction Around Marine Structures LIMAS.

(http://www.isva.dtu.dk/limas:public/limas2.html). The authors thank G. Valls Benavides for his help in developing the testing setup and participating in the first experiments. 


\section{References}

Berrill, J.B., Canou,J., Foray, P., Pautre, J.L., (1992) Piezocone testing of liquefaction sites: Normalization of excess pore pressure" Proc. 10th World Conf. on Earthquake Eng., Madrid.

Bonjean, D., Foray, P. and Michallet, H. (2004) Occurrence of liquefaction in cyclic burial of a structure submitted to wave action and resting on the seabed. Int. Conference on Cyclic Behavior of Soils, CBS' 04, Bochum, Germany, in Cyclic Behavior of Soils and Liquefaction Phenomena, ed. Triantafillydis, Balkema, 10 pages.

Bonjean, D., Foray, P., Piedra-Cueva, I., Michallet, H., Breul, P., Haddani, Y., Mory, M., \& Abadie, S. (2004), Monitoring of the foundations of a coastal structure submitted to breaking waves: occurrence of momentary liquefaction. In Proceedings of Int. Conf. On Offshore and Polar Engineering ISOPE 2004, Toulon, France, May 22-28,Vol. II, pp.585592.

Branque, D. 1998. Etude de l'auto ensouillement des pipelines flexibles soumis à la houle et aux courants marins, PhD Dissertation, Institut National Polytechnique de Grenoble, 397 pages.

Branque, D., Foray, P. \& Labanieh, S. 2001. Etude expérimentale de l’interaction entre les fonds marins et les pipelines flexibles soumis à la houle et aux courants, Revue Française de Géotechnique, 97, pp. 61-78.

Branque, D., Foray, P. \& Labanieh, S. 2002. Wave-induced interaction between soil and flexible pipelines resting on the seabed, in Physical models in Geotechnics, Proc.Intern. Conf. of Physical Modelling in Geotechnics, St John, Newfoundland, Canada, July 2002, Balkema Publishers, pp.271-276.

Brennodden, H., Sveggen, O., Wagner, D.A. \& Murff, J.D. 1986. Full scale pipe-soil interaction tests. In Proceedings of $18^{\text {th }}$ Offshore Technology Conference, OTC 5338, Houston Texas.

Bryndum, M.B., Jacobsen, V. and Thasalis, D.T. 1992. Hydrodynamic forces on pipelines : model tests. J. Offshore Mechanics and Artic Engineering, Trans. ASME, 114:231-241

Cheng,L., Sumer, B.M. \& Fredsoe, J. 2001, Solutions of pore pressure build up due to progressive waves, Int. J. Numerical and Analytical methods in Geomechanics, 2001; 25, pp. 885-907.

Damgaard, J.S \& Palmer, A.C. 2001. Pipeline stability on a mobile and liquefied seabed: a discussion of magnitudes and engineering implications. In Proceedings of $20^{\text {th }}$ Conference on Offshore Mechanics and Arctic Engineering, OMAE’01, Rio de Janeiro, Brazil 
Foray, P., Bonjean, D., and Michallet, H. (2004) Influence of sand liquefaction on the self burial of a pipe submitted to wave action, In Proceedings of Int. Conf. On Offshore and Polar Engineering ISOPE 2004, Toulon, France, May 22-28, Paper n 2004-JSC-225,Vol. II, pp.571-578.

Lambrakos, K.F. 1985. Marine pipeline soil friction coefficient from in-situ testing. In Ocean Engineering, Vol.12, $\mathrm{n}^{\circ} 2$, pp. 131-150.

Lyons, C.G. 1973. Soil resistance to lateral sliding of marine pipelines. In Proceedings of $5^{\text {th }}$ Offshore Technology Conference, OTC 1876, Houston, Texas.

Morison, J.R., O'Brien, M.P., Johnson, J.W. and Schaaf, S.A. 1950. The forces exerted by surfaced waves on piles. J. Petroleum Transactions, AIME, 189:149-154

Morris, D.V., Webb, R.E \& Dunlap, W.A., 1988. Self-burial of laterally loaded offshore pipelines in weak sediments. In Proceedings of $20^{\text {th }}$ Offshore Technology Conference, OTC 5855, Houston, Texas.

Palmer, A.C., Steenfelt J.S. \& Jacobsen, V. 1988. Lateral resistance of marine pipelines on sand. In Proceedings of $20^{\text {th }}$ Offshore Technology Conference, OTC 5853, Houston, Texas.

Sassa, S., Seikiguchi, H. \& Miyamoto, J. 2001. Analysis of progressive liquefaction as a moving boundary problem, Geotechnique 51, N 10, pp. 847-857.

Sumer, B.M., and Fredsøe, J. 1997. Hydrodynamics around cylindrical structures, Advanced Series on Ocean Engineering - vol. 12, World Scientific.

Sumer, B.M., Fredsoe, J., Christensen, S., \& Lind, M.T., 1999. Sinking/floatation of pipelines and other objects in liquefied soils under waves, Coastal Engineering 38, pp. 53-90.

Sumer, BM, Truelsen, C, and Fredsøe, J (2005). "Liquefaction around pipelines under waves," submitted for publication in ASCE J. Waterways, Port, Coastal and Ocean Engineering.

Teh, T. C., Palmer, A.C.\& Damgaard, J.S. 2003. Experimental study of marine pipelines on unstable and liquefied seabed, Coastal Engineering, 50: 1-17.

Veritec, 1988. Recommended practice E 305 on bottom stability design of submarine pipelines. In Veritas Offshore Technology and Service.

Wagner, D.A., Murff, J.D. \& Brennodden, H. 1987. Pipe-soil interaction model. In Proceedings of 19th Offshore Technology Conference, OTC 5504, Houston, Texas.

Wolfram, W.R., Getz, J.R. \& Verley, R.L.P. 1987. Pipestab Project: Improvement design basis for submarine pipeline stability. In Proceedings of the $19^{\text {th }}$ Offshore Technology Conference, OTC 5501, Houston, Texas. 
Table 1. Load controlled testing program

\begin{tabular}{cccc}
\hline Test N & $\begin{array}{c}\text { Density } \\
\text { Index } \%\end{array}$ & Period (s) & $\begin{array}{c}\text { Load } \\
\text { amplitude } \\
(\mathrm{N})\end{array}$ \\
\hline L1 & 35 & 4 & \pm 500 \\
L2 & 35 & 2 & \pm 500 \\
L3 & 60 & 4 & \pm 500 \\
L4 & 60 & 2 & \pm 500 \\
L5 & 60 & 4 & \pm 300 \\
L6 & 60 & 4 & \pm 600 \\
L7 & 60 & 6 & \pm 900 \\
L8 & 60 & 6 & \pm 600 \\
L9 & 60 & 8 & \pm 600 \\
L10 & 60 & 6 & \pm 300 \\
L11 & 35 & 6 & \pm 600 \\
\hline
\end{tabular}

Table 2. Displacement - controlled testing program

\begin{tabular}{cccc}
\hline Test $\mathrm{N}^{\circ}$ & $\begin{array}{c}\text { Density } \\
\text { Index \% }\end{array}$ & Period (s) & $\begin{array}{c}\text { Displacement } \\
\text { amplitude (mm) }\end{array}$ \\
\hline D1* & 60 & 6 & \pm 52 \\
D2 * & 60 & 2 & \pm 10 \\
D3 * & 35 & 1.5 & \pm 5 \\
D4 ** & 35 & 15 & \pm 40 \\
D5 ** & 35 & 15 & \pm 60 \\
D6 ** & 35 & 15 & \pm 80 \\
D7* & 35 & 1.9 & \pm 10.5 \\
D8* & 35 & 4.55 & \pm 10.5 \\
\hline
\end{tabular}

* performed with the actuator set.

** performed with the motor set. 


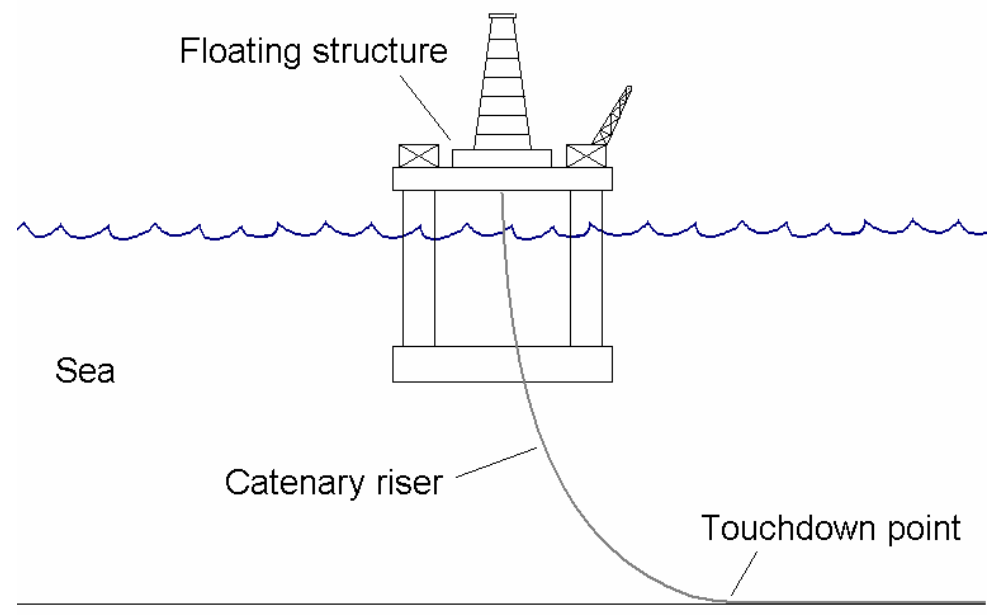

Sea bed

Figure 1: Wave-induced cyclic loading of a catenary riser on the seabed.

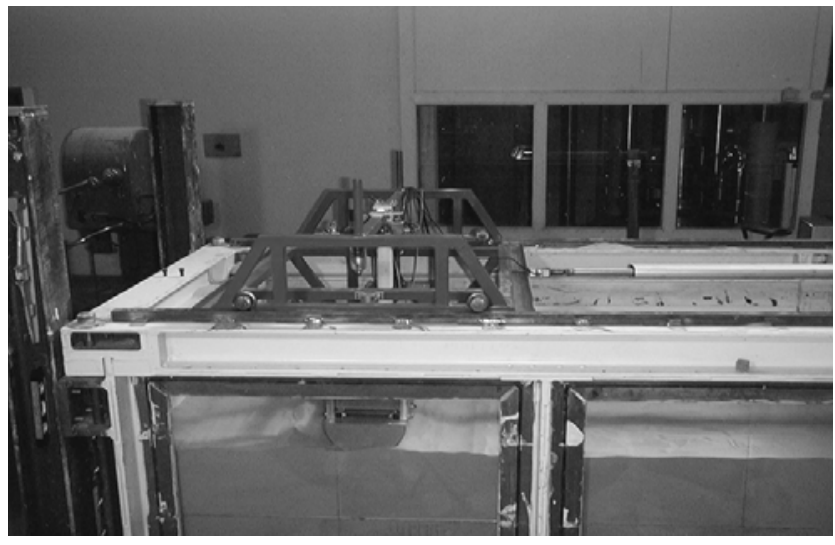

Figure 2: Experimental set up, with the electro-mechanic actuator

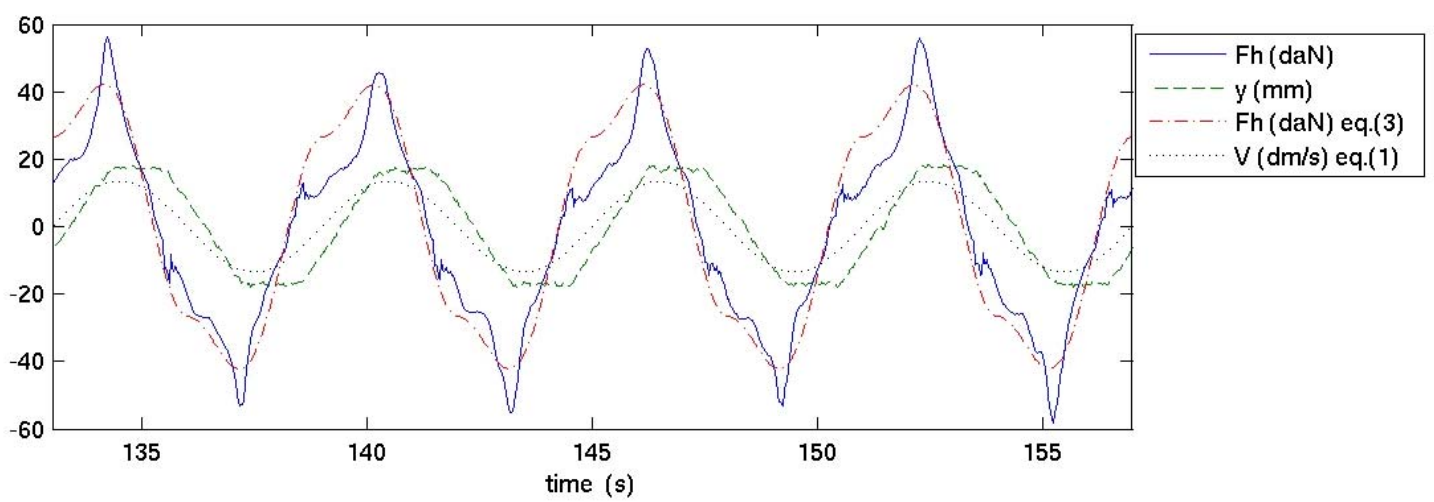


Figure 3 : In-line force obtained from the Morison equation (Fh eq.3) against flow velocity at the bottom ( $V$ eq.1) and measured horizontal force $(F h)$ against horizontal displacement $(y)$ for load controlled test L8. Forces are in daN, with 1 daN $=10 \mathrm{~N}$.

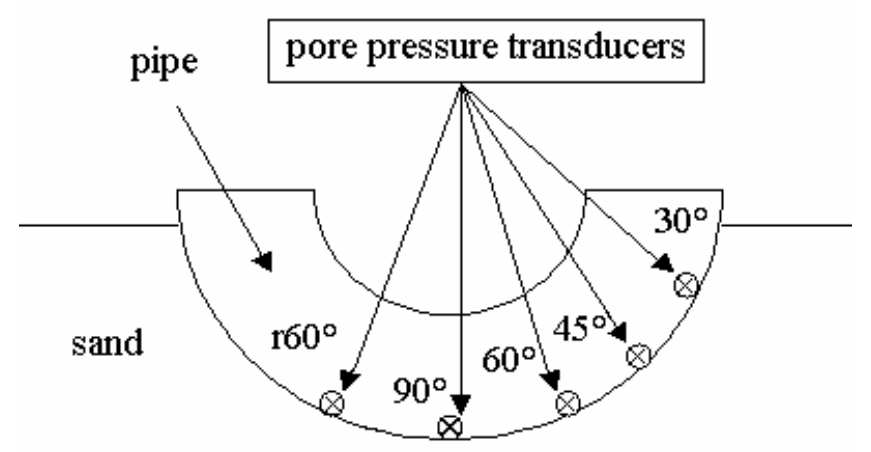

Figure 4: Distribution of the pore pressure sensors along the pipe-soil interface

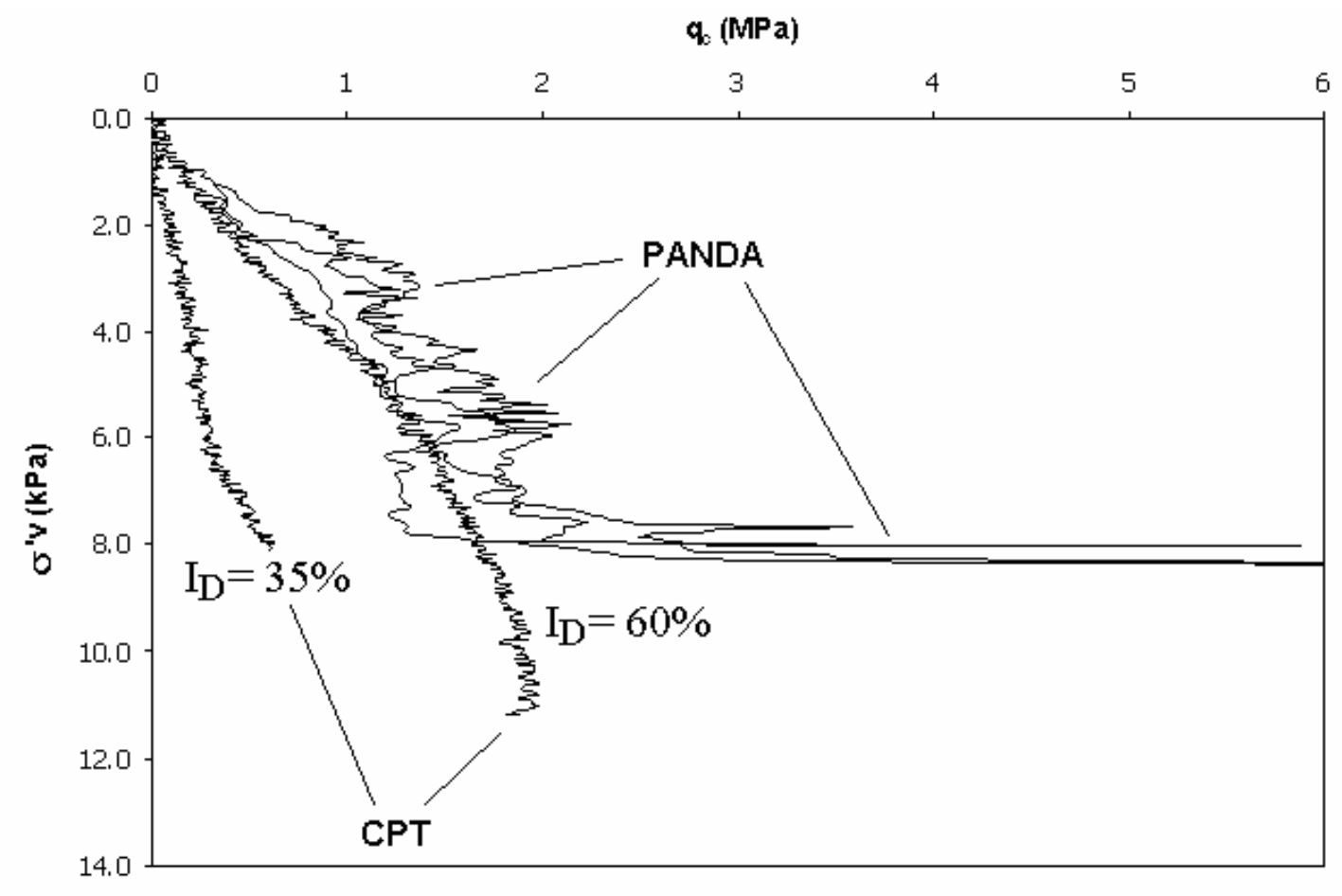

Figure 5 : Penetration curves in Fontainebleau sand. 


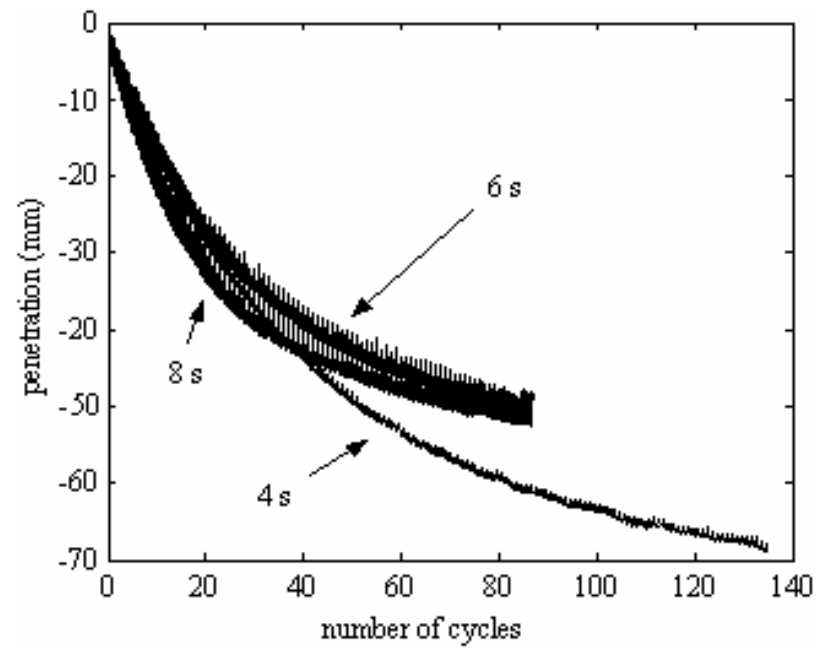

Figure 6: Influence of the loading period on the penetration of the pipe. Maximum applied load: 600 N. Dense sand

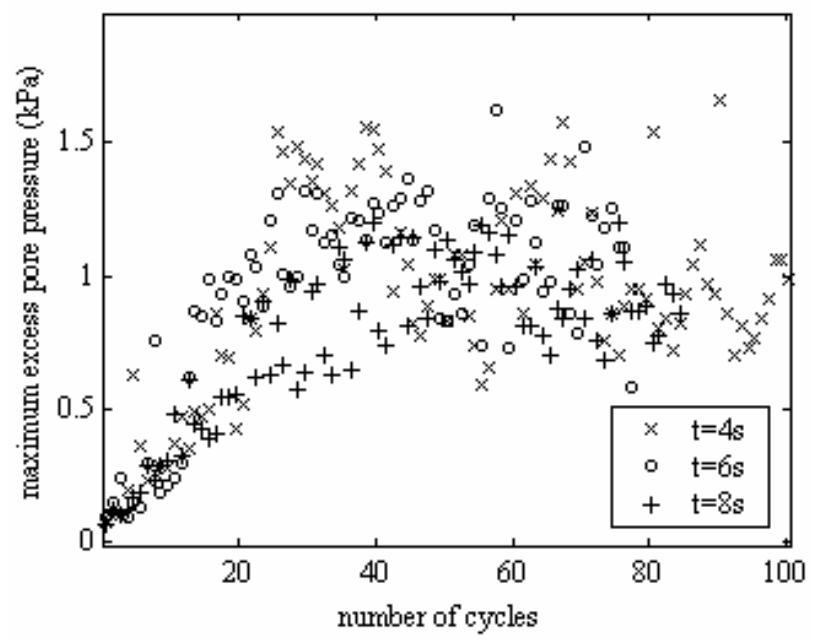

Figure 7: Influence of the loading period on the excess pore pressure at $60^{\circ}$ under the pipe.

Applied force amplitude: 600 N. Dense sand 


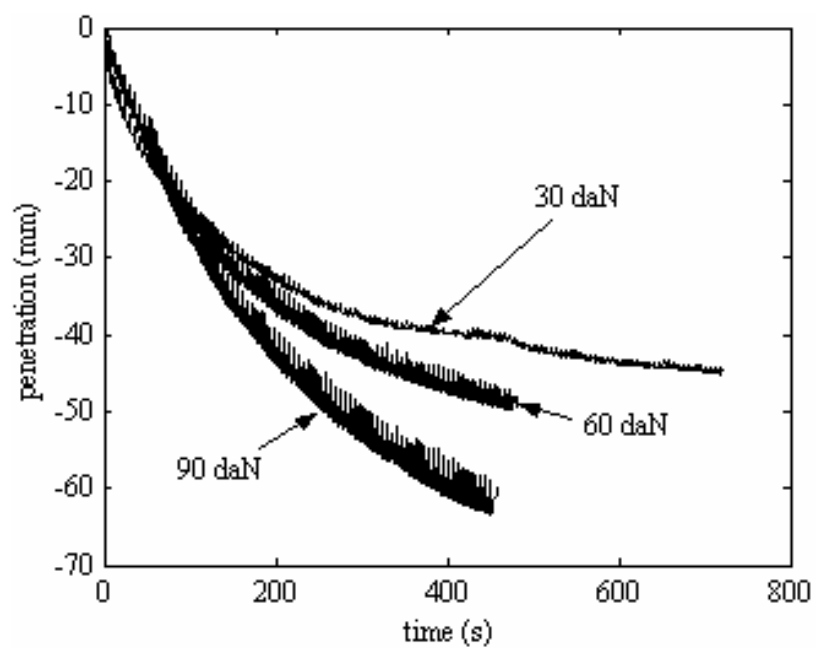

Figure 8: Influence of the load-amplitude on the penetration of the pipe, for a period $\mathrm{T}=6 \mathrm{~s}$.

Dense sand. $1 \mathrm{daN}=10 \mathrm{~N}$.

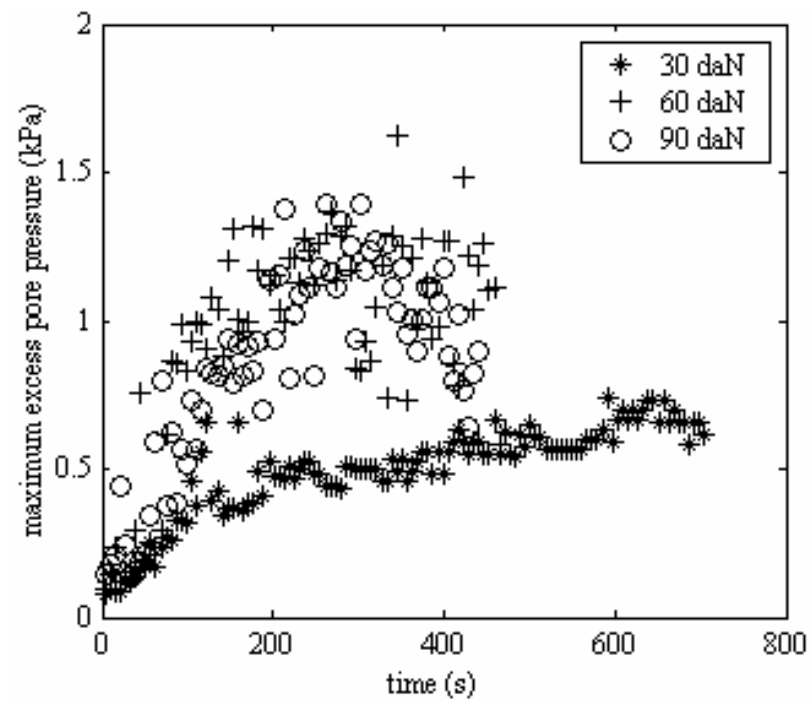

Figure 9: Influence of the load amplitude on the maximum excess pore pressure at $60^{\circ}$ during each cycle. Period 6 s. Dense sand. $1 \mathrm{daN}=10 \mathrm{~N}$. 


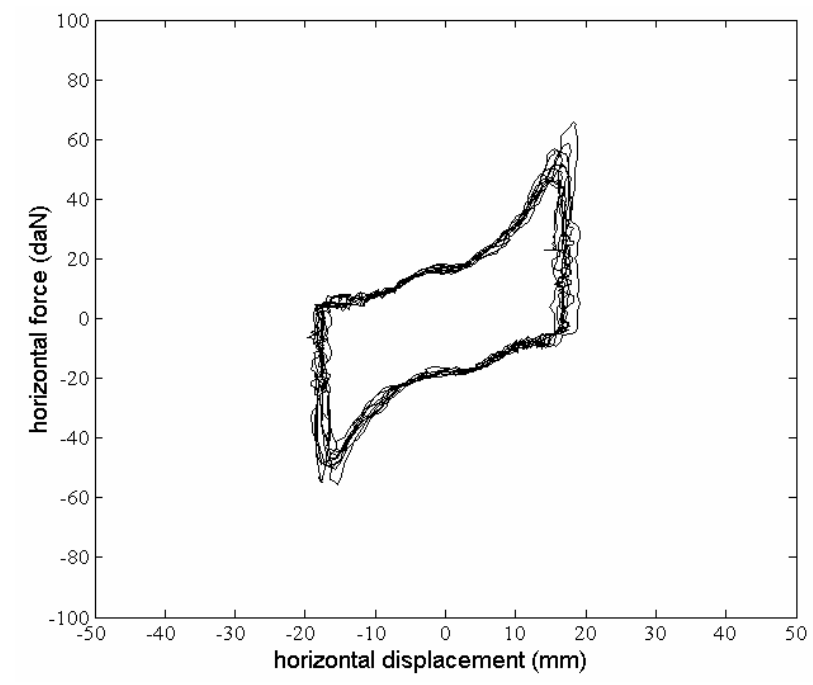

Figure 10a. Cyclic load- horizontal displacement curves for Test L8. Load amplitude $600 \mathrm{~N}$. Period $6 \mathrm{~s}$.

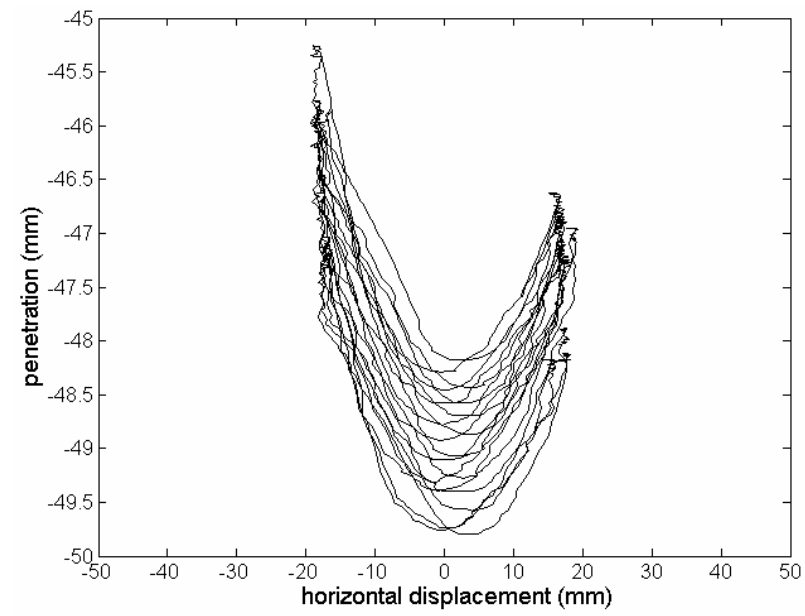

Figure 10b: Cyclic penetration-horizontal displacement curves of the pipe. Test L8. 


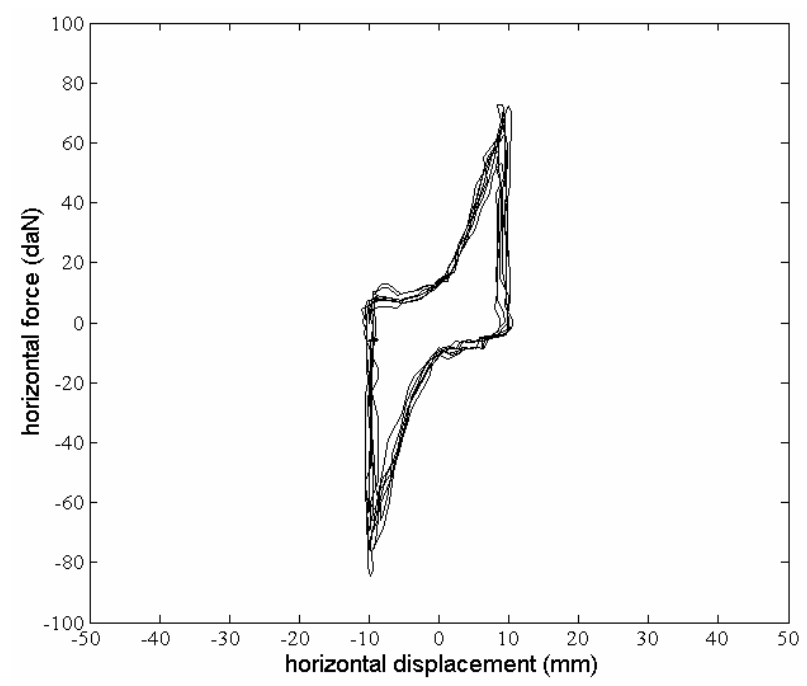

Figure 11: Cyclic load-displacement curves for displacement-controlled test D2 with an amplitude of $10 \mathrm{~mm}$ and a period of $2 \mathrm{~s}$.

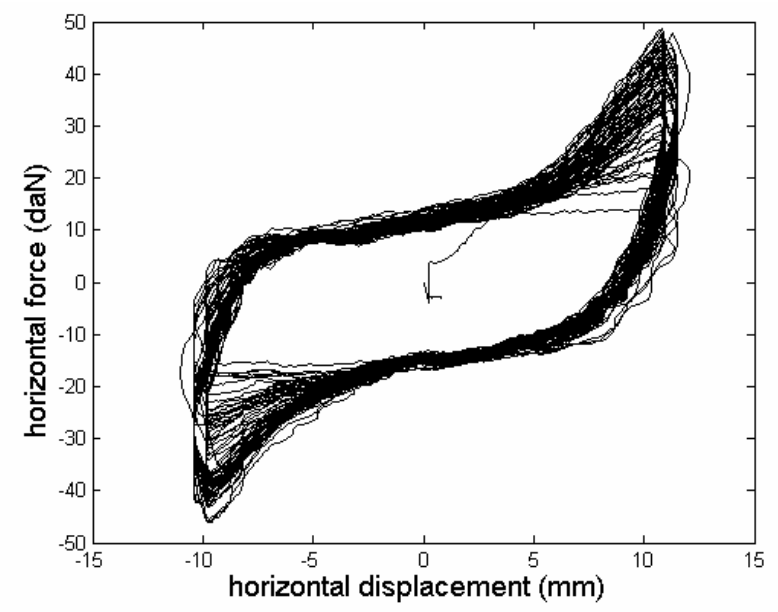

Figure 12: Cyclic load-displacement curves for Test D8 with amplitude $\pm 10.5 \mathrm{~mm}, T=4.55 \mathrm{~s}$. 


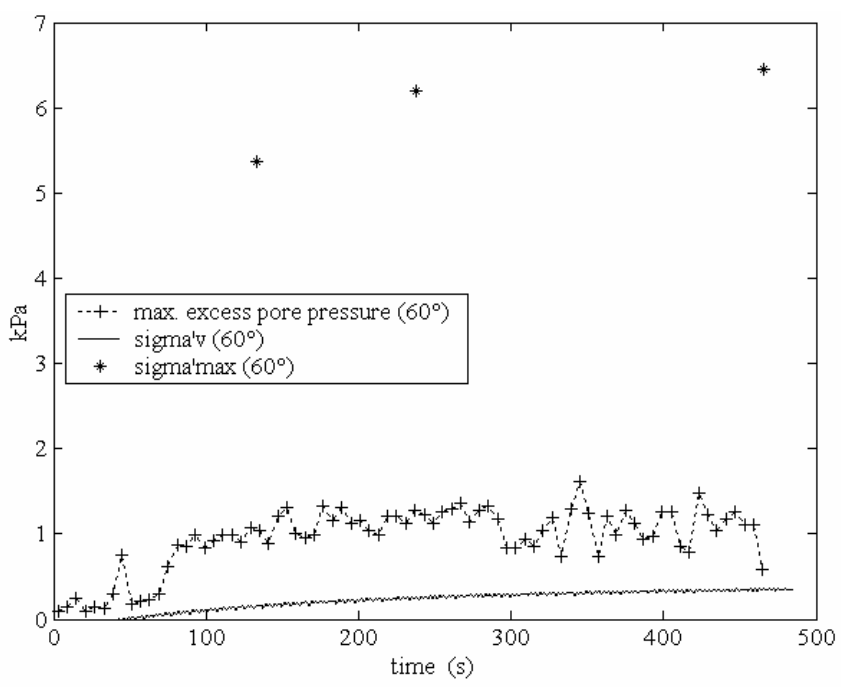

Figure 13: Excess pore pressure at $60^{\circ}$ under the pipe compared to effective vertical stress and passive pressure stress at the same depth during penetration of the pipe. Load controlled test L8. Load amplitude $600 \mathrm{~N}$, period $\mathrm{T}=6 \mathrm{~s}$.
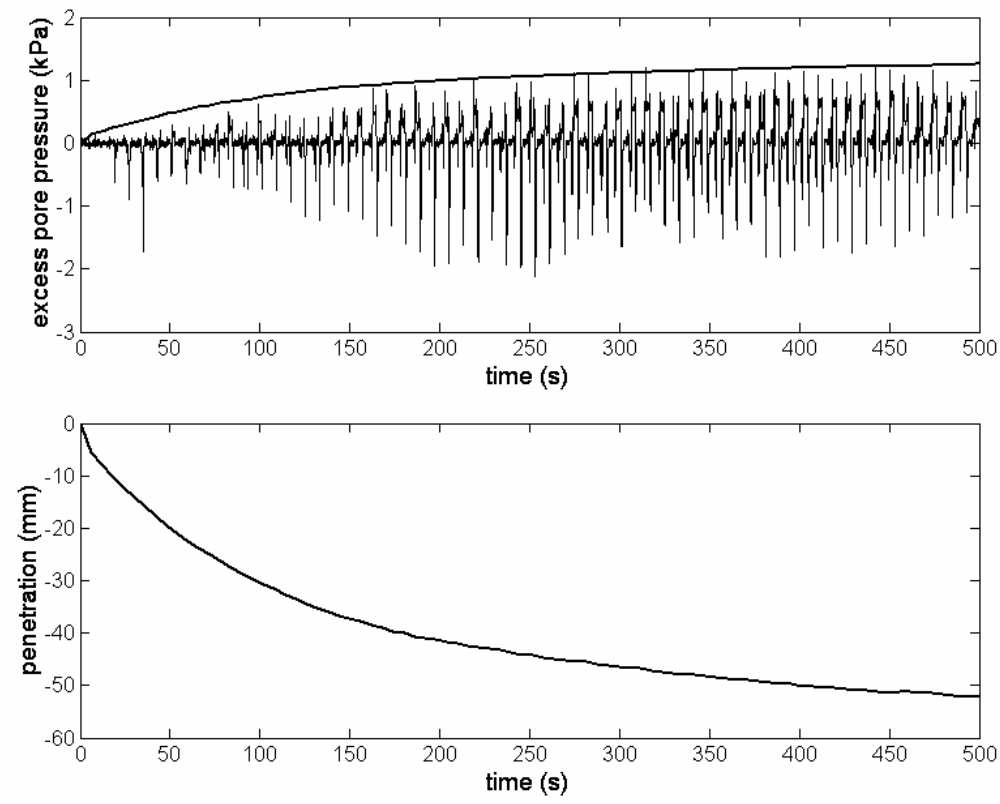

Figure 14: Load controlled test. Amplitude 600 N, period T = 8 s. Dense sand. 


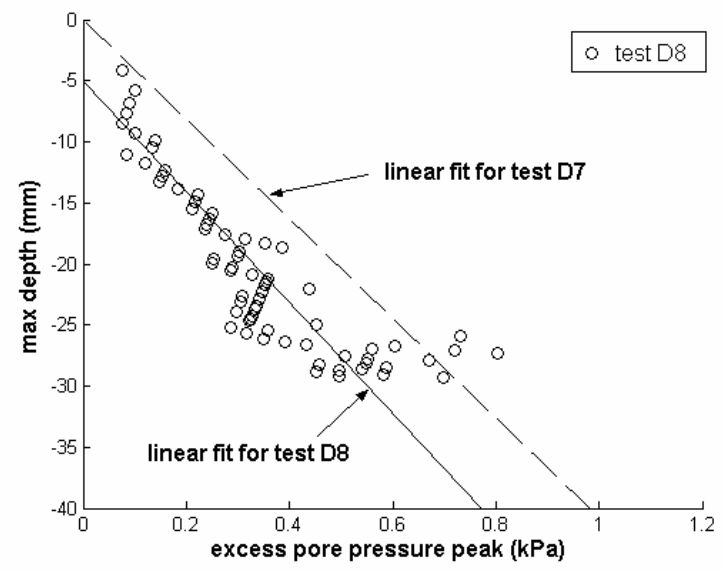

Figure 15: Development of excess pore pressure with pipe penetration. Loose sand. Tests D7 and D8.

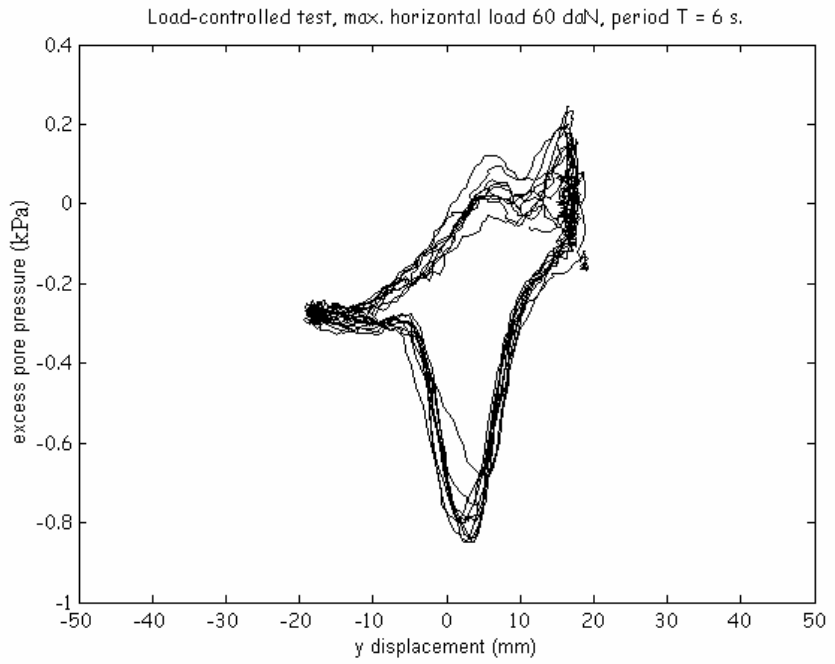

Figure 16: Cyclic pore pressure changes at the pipe-soil interface (sensor at $60^{\circ}$ ), test L8. 


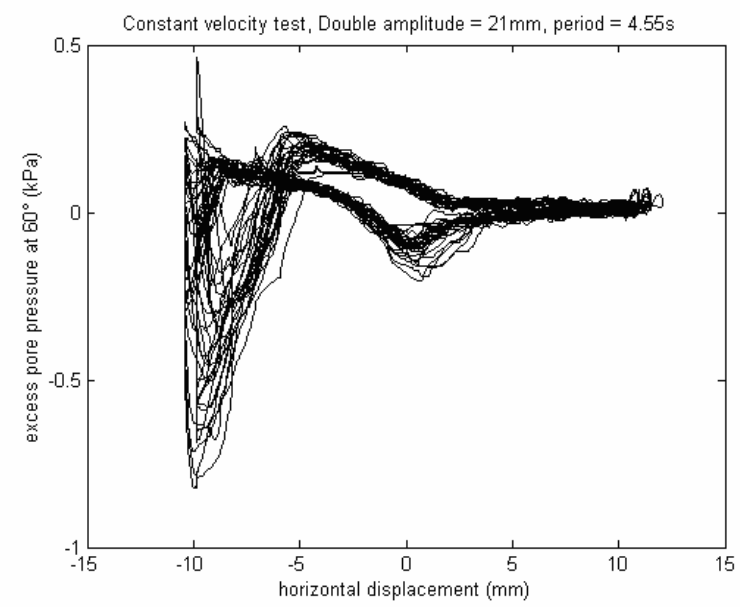

Figure 17: Cyclic pore pressure changes at the pipe-soil interface (sensor at $60^{\circ}$ left). Test D8 (loose sand).

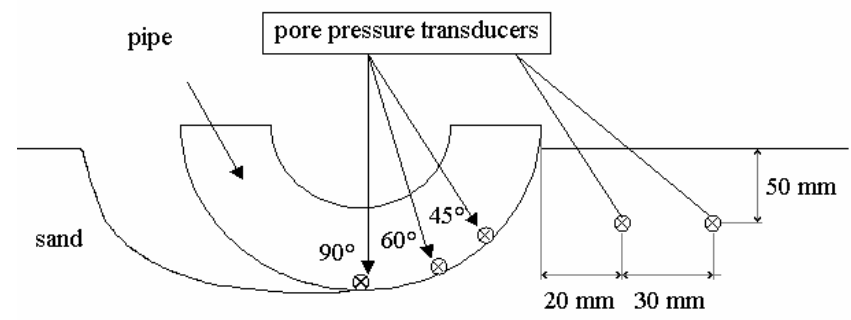

Figure 18: Location of the pore pressure sensors along the pipe and in the soil

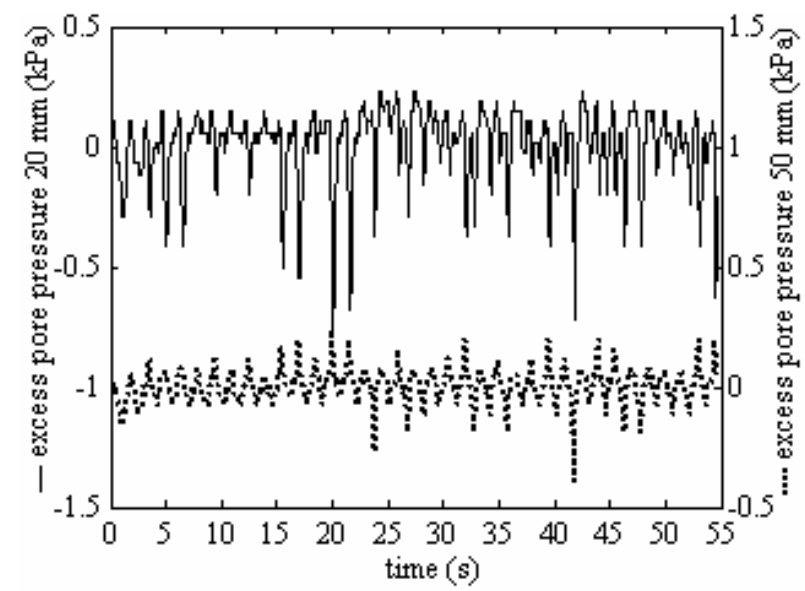

Figure 19: Recording of the pore pressure transducers placed within the soil. Controlled displacement test D3, performed with the electro-mechanical actuator set. Period $T=1.5 \mathrm{~s}$ 

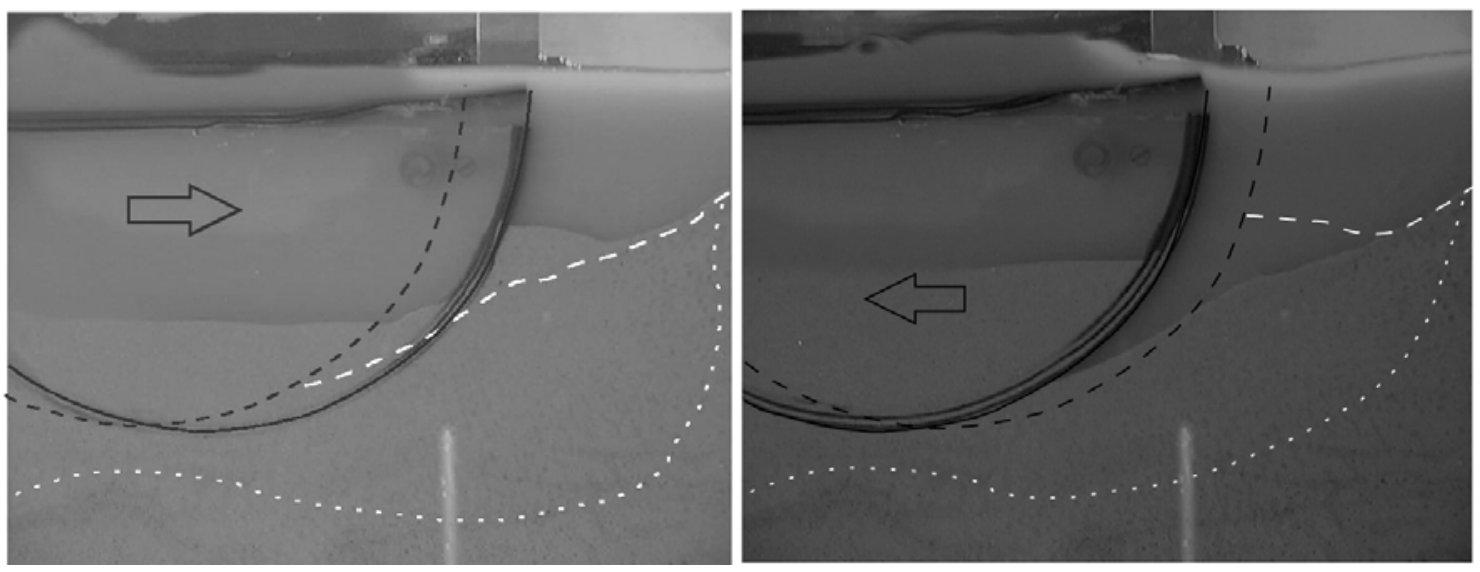

Figure 20: Video frames $1 \mathrm{~s}$ apart at the maximum excursion of the pipe (controlled force test L4, maximum applied horizontal force: $500 \mathrm{~N}, T=2 \mathrm{~s})$. The pipe position and soil/water interface at the preceding half-period are plotted with dashed line (black and white respectively). The dotted line bounds the area where grain motion was observed during the preceding half-period.

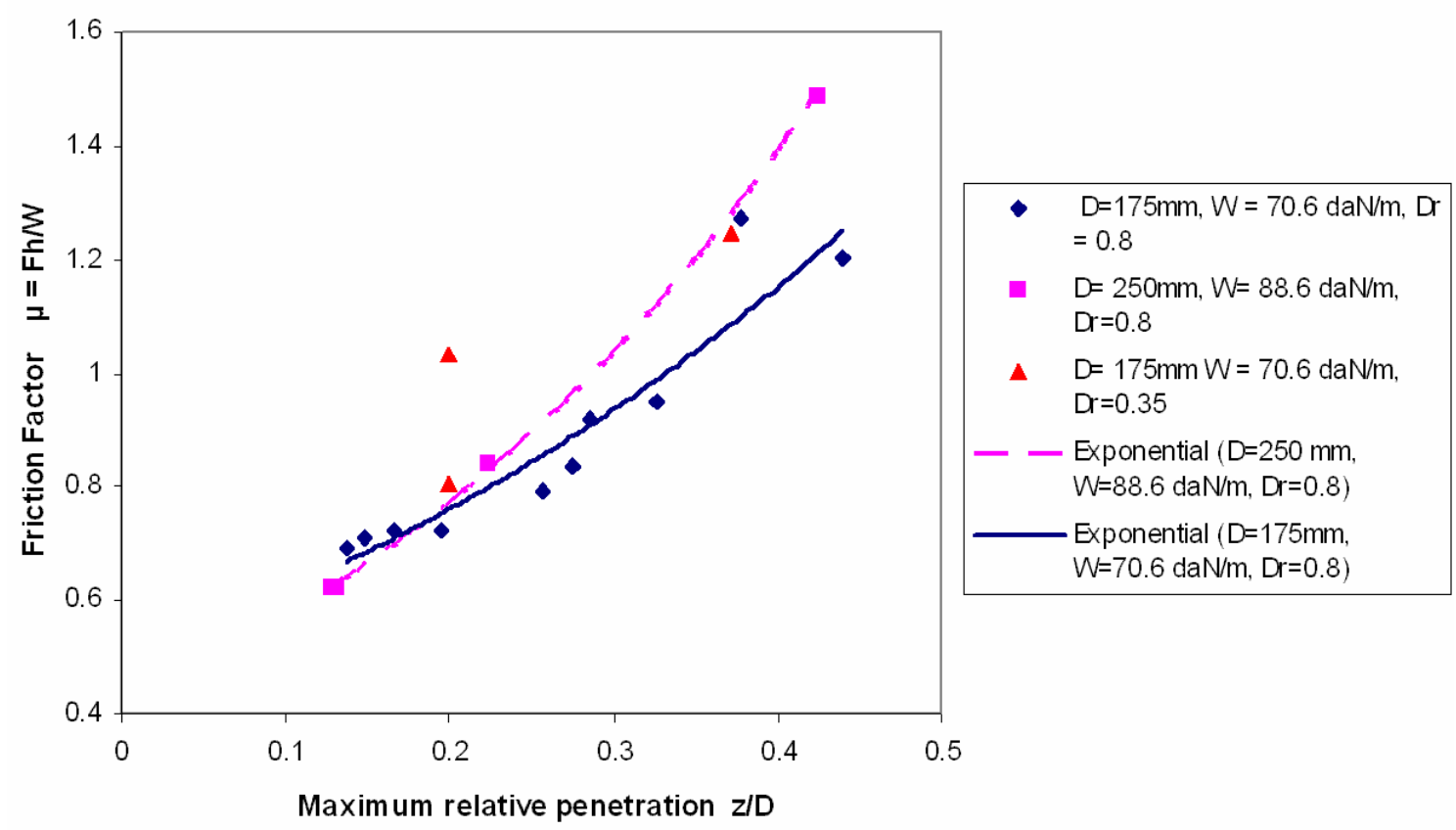

Figure 21: Equivalent friction factors obtained by Branque et al (2002) 


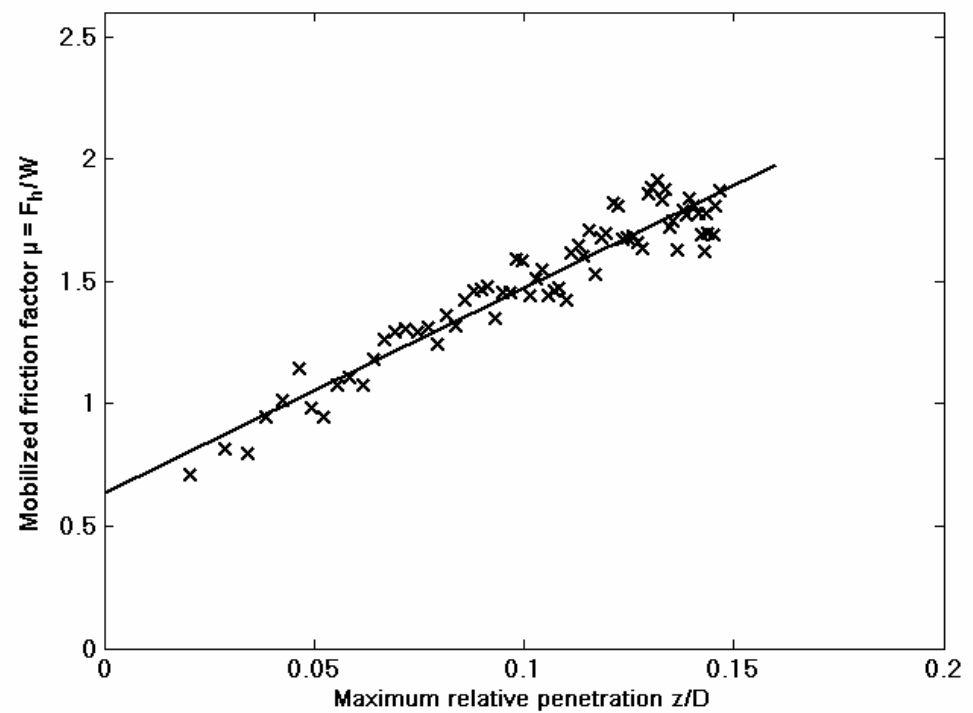

Figure 22: Evolution of the mobilized friction factor $\mu$ with pipe penetration during Test D8. 
List of figure captions :

Figure 1: Wave-induced cyclic loading of a catenary riser on the seabed.

Figure 2: Experimental set up, with the electro-mechanic actuator

Figure 3 : In-line force obtained from the Morison equation ( $F h$ eq.3) against flow velocity at the bottom ( $V$ eq.1) and measured horizontal force $(F h)$ against horizontal displacement $(y)$ for load controlled test L8. Forces are in daN, with $1 \mathrm{daN}=10 \mathrm{~N}$.

Figure 4: Distribution of the pore pressure sensors along the pipe-soil interface

Figure 5 : Penetration curves in Fontainebleau sand.

Figure 6: Influence of the loading period on the penetration of the pipe. Maximum applied load: 600 N. Dense sand

Figure 7: Influence of the loading period on the excess pore pressure at $60^{\circ}$ under the pipe. Applied force amplitude: 600 N. Dense sand

Figure 8: Influence of the load-amplitude on the penetration of the pipe, for a period $\mathrm{T}=6 \mathrm{~s}$. Dense sand. $1 \mathrm{daN}=10 \mathrm{~N}$.

Figure 9: Influence of the load amplitude on the maximum excess pore pressure at $60^{\circ}$ during each cycle. Period 6 s. Dense sand. $1 \mathrm{daN}=10 \mathrm{~N}$. 
Figure 10a. Cyclic load- horizontal displacement curves for Test L8. Load amplitude $600 \mathrm{~N}$. Period 6 s.

Figure 10b: Cyclic penetration-horizontal displacement curves of the pipe. Test L8.

Figure 11: Cyclic load-displacement curves for displacement-controlled test D2 with an amplitude of $10 \mathrm{~mm}$ and a period of $2 \mathrm{~s}$.

Figure 12: Cyclic load-displacement curves for Test D8 with amplitude $\pm 10.5 \mathrm{~mm}, T=4.55 \mathrm{~s}$.

Figure 13: Excess pore pressure at $60^{\circ}$ under the pipe compared to effective vertical stress and passive pressure stress at the same depth during penetration of the pipe. Load controlled test L8. Load amplitude $600 \mathrm{~N}$, period T = $6 \mathrm{~s}$.

Figure 14: Load controlled test. Amplitude $600 \mathrm{~N}$, period T = 8 s. Dense sand.

Figure 15: Development of excess pore pressure with pipe penetration. Loose sand. Tests D7 and D8.

Figure 16: Cyclic pore pressure changes at the pipe-soil interface (sensor at $60^{\circ}$ ), test L8.

Figure 17: Cyclic pore pressure changes at the pipe-soil interface (sensor at $60^{\circ}$ left). Test D8 (loose sand).

Figure 18: Location of the pore pressure sensors along the pipe and in the soil

Figure 19: Recording of the pore pressure transducers placed within the soil. Controlled displacement test D3, performed with the electro-mechanical actuator set. Period $T=1.5 \mathrm{~s}$ 
Figure 20: Video frames $1 \mathrm{~s}$ apart at the maximum excursion of the pipe (controlled force test L4, maximum applied horizontal force: $500 \mathrm{~N}, T=2 \mathrm{~s}$ ). The pipe position and soil/water interface at the preceding half-period are plotted with dashed line (black and white respectively). The dotted line bounds the area where grain motion was observed during the preceding half-period.

Figure 21: Equivalent friction factors obtained by Branque et al (2002)

Figure 22: Evolution of the mobilized friction factor $\mu$ with pipe penetration during Test D8. 